\title{
Topical Treatment Modalities for Old World Cutaneous Leishmaniasis: A Review
}

\author{
Alavi-Naini R. ${ }^{1}$, Fazaeli A. ${ }^{2}$, O'Dempsey T. $^{3}$ \\ ${ }^{1}$ Research Centre for Infectious Diseases and Tropical Medicine, Zahedan University \\ of Medical Sciences, Zahedan, Iran; \\ ${ }^{2}$ Department of Parasitology, School of Medicine, Zanjan University of Medical \\ Sciences and Health Services, Zanjan, Iran; \\ ${ }^{3}$ Liverpool School of Tropical Medicine, Liverpool, UK \\ Received October 6, 2011; Accepted April 11, 2012.
}

Key words: Cutaneous leishmaniasis - Old world - Topical treatment

\begin{abstract}
Diagnosis and therapy of cutaneous leishmaniasis (CL) can be difficult due to the variability of the clinical pictures and resistance to therapy. There is no vaccine currently available for CL. The aim of the present review is to describe different topical treatment modalities for old world CL. The mainstays of treatment for old world $C L$ are pentavalent antimony compounds which are administered parenterally or intralesionally. New topical treatment alternatives have been available within the past few years. Amongst several treatments used topically, physical therapies including cryotherapy, heat therapy and $\mathrm{CO}_{2}$ laser are promising for the treatment of old world CL. Along with that, other randomized placebo controlled trials should be designed to find new effective therapeutic regimens.
\end{abstract}

Mailing Address: Assoc. Prof. Asghar Fazaeli, PhD., Department of Parasitology, School of Medicine, Zanjan University of Medical Sciences and Health Services, 4513956111 Zanjan, Iran; Phone: +98 24142403 01-3 (ext. 241);

Fax: +98 24142495 53; e-mail: afparm1@yahoo.co.uk 


\section{Introduction}

Leishmaniasis is a vector-borne disease caused by an obligate intracellular protozoon called Leishmania which resides mostly in macrophages. Leishmania infections including cutaneous leishmaniasis $(\mathrm{CL})$ affects 88 countries, of which 72 are developing countries. Ninety percent of $\mathrm{CL}$ cases occur in Middle East and South American countries (Singh and Sivakumar, 2004). CL is a serious public health problem with an approximate incidence of 2 million new cases per year. The majority of old world $C L$ is caused by one of two species of parasites; L. tropica which is classically an urban disease agent producing relatively benign (dry) ulcers and $L$. major that is the cause of rural type which usually develops larger and more destructive (wet) ulcers. L. aethiopica is found in Ethiopia and Kenya. New foci of L. tropica have recently been reported in several endemic countries, including Iran (Yaghoobi-Ershadi et al., 2004), Afghanistan, Pakistan, Syria, and Israel (Reithinger et al., 2003). We also found a new focus of $\mathrm{CL}$ in a border area at south-eastern Iran with causative agent of $L$. major (Fazaeli et al., 2008, 2009). The aim of therapeutic regimens is clinical healing and parasite eradication but the efficacy of anti-leishmanial drugs is controversial (Reithinger et al., 2007). In addition to several confounders in the treatment of $\mathrm{CL}$, drug resistance of the parasite against some conventional compounds, has been reported (Ouellette et al., 2004; Croft et al., 2006). Further, dissimilar clinical features of the same type of leishmaniasis, indicating possible genetic variation of the Leishmania parasite populations (Fazaeli et al., 2008), can be of major causes of the diverse treatment effects. Direct detection and identification of the Leishmania parasites at the species level, using direct PCR (Fouladi et al., 2007) is also of great value particularly for the evaluation of drugs efficacy and clinical trials.

The treatment of choice of $\mathrm{CL}$ is pentavalent antimony compounds with a cure rate of about $85 \%$. However, the adverse effects of this toxic drug are debating. These antimony compounds, either sodium stibogluconate or meglumine antimoniate (Glucantime), are widely prescribed despite their toxicity, high cost and difficult administration (Croft and Yardley, 2002). Local treatment modalities including intralesional infiltration of meglumine antimoniate, topical treatment with several medications, photodynamic therapy, localized heat therapy, cryotherapy and laser therapy could be effective against $L$. major or $L$. tropica which are the most common causes of old world CL (Reithinger et al., 2007). The objective of this review article is to describe different topical treatment modalities in both clinical and experimental studies for old world CL.

\section{Parentral and intralesional treatments}

Pentavalent antimony compounds

The first effective drug for the treatment of leishmaniasis was ureastibamine. It was discovered as an effective compound in 1912 but introduced for the treatment of leishmaniasis by Professor Upendranath Brahmchari who was nominated for 
the Nobel Prize in 1929 (Singh and Sivakumar, 2004). Later on, the new effective compounds, related to antimony compounds were introduced to the medical literature and were found more effective with fewer side effects. Two popular types are sodium stibogluconate (SSG) or Pentostam and meglumine antimoniate (MG) or Glucantime; both are injectable and applicable with different dosages $(10-20 \mathrm{mg} /$ day) for 20 to 28 days (Reithinger et al., 2007). Their precise mechanism of action is not known; probably those compounds can inhibit glycolytic enzymes and decrease fatty acid oxidation in amastigotes. The inhibition process, described recently (Croft et al., 2006), is dose dependent and decreases the available amount of ATP and GTP (Singh and Sivakumar, 2004).

Intralesional administration of the antimony compounds is the standard form of treatment for persistent, multiple and/or large lesions. It should be noted that combination of intramuscular and intralesional administrations of MG was found to be superior to the intralesional application alone (Munir et al., 2008). The treatment recommended by WHO advisory committee, is using SSG or MG for at least 20 days. Intralesional route should be relied on the infiltration of the compound into the upper and mid-dermis and must produce complete blanching of the base of the lesion. Treatment efficacy ranged between 81 and 97\% (Uzun et al., 2004). However, not only the drug is expensive itself, but also the medical attention for preventing side effects which are frequent and sometimes very dangerous, make the treatment further expensive. Factors associated with treatment failure, included the presence of more than 3 cutaneous lesions, previous treatment, body weight above $68 \mathrm{~kg}$ and incomplete treatment schedule. The last factor has the highest odds ratio and body weight is possibly associated with the limitation of the maximum daily dose (Rodrigues et al., 2006). These results help to identify patients at risk of treatment failure of cutaneous leishmaniasis with antimony compounds therapy. Pancreatitis, cardiotoxicity, pancytopenia and peripheral neuropathy are the main side effects. Toxicity reduction, economic cost and poor compliance of the drug will be the major foci of the researchers to produce new alternative compounds (Singh and Sivakumar, 2004; Reithinger et al., 2007). As it was noted earlier, clinical variation of the $\mathrm{CL}$ wounds implying genetic variability of the causative Leishmania parasite (Fazaeli et al., 2008), can be another dimension to consider when developing a new compound; in other word, the broad coverage of the drug effect on different genotypes and populations of the parasite should also be taken into account.

\section{Amphotericin B}

Deoxycholate formulation is another antifungal drug which has recently been used for CL. It was discovered in 1956 from a bacterium of Streptomyces genus. The mechanism of action is binding to the ergosterol of the fungal membrane which is the main sterol of fungi and leishmania amastigotes and causes selective inhibition of cell membrane synthesis (Singh and Sivakumar, 2004). Ergosterol is not the main sterol in human cell membranes so it cannot make major injuries in 
the human cells. It was tested in many patients with kala-azar (Sundar et al., 2007) but there are only some restricted studies with successful results for treatment of cutaneous leishmaniasis (Amato et al., 2004). In some new formulations, deoxycholate replaced by some types of lipids, i.e. AmBisome (Davidson and Russo, 1994), Amphocil (Frankenburg et al., 1998) and Abelcet (Sundar et al., 2003). AmBisome is a lyophilized preparation of liposomal amphotericin B consisted of specific proportions of amphophilic substances, including phosphatidylcholine, distearoylphosphatidylglycerol and cholesterol (Proffitt et al., 1991). Amphocil is a mixture of amphotericin B and cholesteryl sulphate complex (Stevens, 1994). In Abelect complex, two phospholipids including dimyristoylphosphatidylcholine (DMPC) and L- $\alpha$-dimyristoylphosphatidylglycerol (DMPG) cover the drug (Wasan et al., 2007). Lipid formulations of amphotericin are now competitive to antimony compounds. Several newly performed studies supported the efficacy of the liposomal amphotericin B on CL without reporting remarkable adverse effects. They are less toxic but more effective. However, the central nervous system toxicity as a potential side effect of this drug should be taken into notice (Glasser and Murray, 2011).

\section{Topical treatment}

Parenteral therapy, currently available for cutaneous leishmaniasis, is painful and potentially has serious side effects in the location of injection. Therefore, it would be valuable to provide topical drugs with good efficacy. Topical treatment is steadily a controversial way for local killing of the parasites, although the results with different compounds are debating. The interpretation of results is probably difficult, due to nonstandard definition of the disease and cure. It is especially useful for patients who cannot tolerate pain and discomfort during and after injection of antimony compounds.

\section{Topical formulations (ointment, solution or gel)}

Imidazoles

The principle mechanism described for the efficacy of antifungal imidazoles is the inhibition of ergosterol biosynthesis from acetate via squalene and lanosterol which is similar to that in yeast and other fungi (Arana et al., 2001a; Singh and Sivakumar, 2004). Topical clotrimazole and miconazole were used for the treatment of CL in Saudi Arabia for one month. In $16 \%$ of the first group, lesions were completely healed but no one in the miconazole group had been cured completely (Singh and Sivakumar, 2004). Larbi and colleagues (1995) conducted a double blind study, comparing $1 \%$ topical clotrimazole versus $2 \%$ miconazole in eastern Saudi Arabia. Sixty-seven percent were cured completely or healed prominently in the first group but in the miconazole group, only $35 \%$ of the patients responded clinically. Although topical ketoconazole is a safe drug but did not drastically change the course of $\mathrm{CL}$ in four Afghani patients (Storer and Wayte, 2005). However, the number of 
trialed cases is too limited for a distinct conclusion. It seems that oral ketoconazole, particularly the hydrolyzed formulation, is more effective than the topical form (Singh and Sivakumar, 2004). Because of potential side effects and high costs of fluconazole, it is unlikely that any systemic therapy will become the first-choice therapy for uncomplicated Old World cutaneous leishmaniasis (Zvulunov et al., 2003).

In an experimental study, the efficacy of topical fluconazole in comparison with topical paromomycin was evaluated in L. major-infected BALB/c mice by Mussi et al. (2007). They found significantly higher efficacy with paromomycin.

In Leishmania tropica infections, there was good evidence of benefit for the use of $200 \mathrm{mg}$ oral itraconazole for 6 weeks comparing to placebo (González et al., 2008).

Systemic itraconazole alone was demonstrated to be inferior to combination therapy in cutaneous leishmaniasis (Al-Mutairi et al., 2009). Topical formulation of this drug for treatment of cutaneous leishmaniasis has not been reported in the literature.

\section{Paromomycin}

Paromomycin or Aminosidine, a broad-spectrum aminoglycoside derivative (Arana et al., 2001b), is also used with variable cure rates. Its antiparasitic action has not been seen with the other aminoglycosides (Singh and Sivakumar, 2004). In a recent study, paromomycin was observed to inhibit in vivo protein synthesis in the leishmania promastigote stage and consequent reduction of the proliferation rate of the parasite (Fernández et al., 2011). The dosage is different between two to three times topical application of the drug for 10 to 30 days (Reithinger et al., 2007). Different studies, comparing the efficacy of treatment between paromomycin and local injection of meglumine antimoanate (Shazad et al., 2005) and between paromomycin and photodynamic therapy (Asilian and Davami, 2006) revealed cure rate of $68 \%$ and $42 \%$ in paromomycin treated patients, respectively. The results did not present clinical significance between treated groups. Iraji and Sadeghinia (2005) reported that using topical 15\% paromomycin, twice daily for one month, did not have prominent clinical effect on patients with $\mathrm{CL}$. Comparing the effect of paromomycin ointment which is topical paromomycin mixed with methylbenzethonium chloride (MBCL) or urea with $M G$ revealed that neither does had a statistically significant effect but all of them revealed their peculiar side effects (Neva et al., 1997; Armijos et al., 2004). Another report did not disclose a complete response to the topical paromomycin in Croatian patients (Stanimirovic et al., 1999). Treatment failure for paromomycin versus MG as the gold treatment also was reported after a 3 month course of therapy. Seventy-two percent of the first group versus $40 \%$ of the second group did not access the treatment milestones in the study (Faghihi and Tavakoli-kia, 2003). Different formulations (mixture) of paromomycin ointments (15-20\%) with/without MBCL (12\%) or urea (10\%) were introduced but the results were equivocal and were not convincing (Grogl et al., 
1999; Arana et al., 2001b). Adding 12\% concentration of benzethonium chloride, cetalkonium chloride or dimethyl sulfoxide, all incorporated in white soft paraffin, could effectively cure the disease or healed the lesion significantly in BALB/c mice (El-On et al., 1984). Although many trials were undertaken, it is very difficult to comparatively discuss them (Arana et al., 2001b). The enhanced efficacy of topical paromomycin gel was confirmed, when it was used in combination with oral miltefosine in L. major-infected mice (Aguiar et al., 2009).

Ointment containing 15 percent paromomycin is believed to be the treatment of choice for Old World cutaneous leishmaniasis in Israel (where L. major is also the most common pathogen) with cure rate of 76 to 86 percent after a single two-week course of daily topical application (El-On et al., 1992; Zvulunov et al., 2003). Topical application of the liposomal form of paromomycin, experimentally evaluated in vivo, is believed to provide a promising effective topical treatment for CL (Carneiro et al., 2010).

\section{Amphotericin B}

Making solutions with ethanol and Amphocil led to prominent decrease in the size of skin lesion in murine CL with low serum level of amphotericin B (Frankenburg et al., 1998). Topical liposomal amphotericin B (in 50 patients) compared with intralesional glucantime (in 60 patients) showed similar efficacy in the treatment of cutaneous leishmaniasis in Iran (Layegh et al., 2011). Additional clinical trials to confirm further, the suitability of this promising topical alternative are recommended.

\section{Sitamaquine}

Sitamaquine, a primaquine analogue as an antimalarial drug has been reported to be toxic with low efficacy in kala-azar treatment (Sundar and Rai, 2002; Loiseau et al., 2011). The most frequent adverse effects are vomiting, dyspepsia, cyanosis and nephritic syndrome secondary to glomerulonephritis (Jha et al., 2005). Sitamaquine topical formulations did not reveal any prominent effect on lesion progression or parasite burden of CL in an experimental study (Garnier et al., 2006). However, there is little known about this compound efficacy against $C L$ and requires further evaluation.

\section{Buparvaquone}

Buparvaquone is a hydroxynaphthoquinone derivative which cannot diffuse through skin contrary to its prodrug formulation (Mantyla et al., 2004). Quite few reports of the treatment effect of this compound against leishmaniasis are available (Garnier et al., 2007). It was shown that both hydrous gel and water-in-oil emulsion formulations of buparvaquone significantly reduced the size of cutaneous lesion and cutaneous parasite burden in experimental studies (Garnier et al., 2007). 


\section{Immunomodulator as an adjuvant}

Imiquimod

Imiquimod is a new immunomodulatory agent. In a randomized controlled trial of the new world $\mathrm{CL}$, it was shown that in all patients treated with imiquimod alone, the disease was relapsed after treatment discontinuation but all patients treated with combination of imiquimod and MG were cured (Arevalo et al., 2007). Similar studies in Peruvian patients revealed the same results with small scar tissue, so it was proposed to recommend for the facial lesions (Miranda-Verastegui et al., 2005). Other reports in old world cutaneous leishmaniasis confirmed treatment failure when topical imiquimod cream used alone and its additive effect when used in association with antimony compounds (Arevalo et al., 2001; Seeberger et al., 2003). In another study, no beneficial effect was reported with combination therapy of imiquimod and MG against L. tropica (Firooz et al., 2006). Immunotherapy of L. major-infected mice, with imiquimod combined with MG chemotherapy showed the efficacy higher than that of imiquimod alone (Khalili et al., 2011). It seems that the available reports are insufficient, requiring further studies.

\section{Physical therapy}

Cryotherapy

Cryosurgery is not a new mode of treatment for $\mathrm{CL}$. Using $\mathrm{CO}_{2}$ cryomachine resulted in a 100\% cure rate for 30 patients without any scar (Bassiouny et al., 1982). Later, liquid nitrogen was reported to have the same effects (Leibovici and Aram, 1986). Combination therapy of cryosurgery and glucantime were found to be much more impressive than each of the two modalities when used alone (el Darouti and al Rubaie, 1990). Two or three cycles of 10 to 30 seconds freezing with a three-week interval limit is used. The results were stated as satisfactory with rare and infrequent complication (al-Majali et al., 1997; Panagiotopoulos et al., 2005).

Combination of cryotherapy with intralesional injections of MG or sodium stibogluconate was shown to be more effective than the use of intralesional MG alone (Asilian et al., 2003).

A randomized clinical trial of children in Iran showed that cryotherapy is an effective treatment for cutaneous leishmaniasis in children comparing to intralesional glucantime. Simplicity, lower cost, low rate of serious complications and greater tolerability can make cryotherapy an appropriate alternative treatment for cutaneous leishmaniasis in children (Layegh et al., 2009).

The results of treatment of cutaneous leishmaniasis in Dutch troops in northern Afghanistan revealed that intralesional injections of antimony compounds with or without cryotherapy were satisfactory, but $19.5 \%$ of patients received secondary treatment with miltefosine (van Thiel et al., 2010). Cryotherapy is found highly effective in the treatment of dryer and smaller $(<1 \mathrm{~cm})$ lesions, but for the treatment of large lesions, it needs to be administered in combination with intralesional antimony compounds (Asilian et al., 2004a; Bumb and Satoskar, 2011). 


\section{Thermotherapy}

Thermotherapy is a simple and cost effective way improving the results of treatment with antimony compounds. A clinical trial on thermotherapy using radiofrequency waves with $50{ }^{\circ} \mathrm{C}$ temperature for 30 seconds provided effective, well tolerated and rapid treatment modality (Reithinger et al., 2005). Potential mechanisms include direct destruction of parasites by heat.

There are a number of other studies supporting the suitability of this treatment method (i.e. Vega et al., 2009; Aronson et al., 2010).

\section{Photodynamic therapy}

Light mediated cytolysis of leishmania amastigotes and promastigotes is new technique in the treatment of CL (Asilian and Davami, 2006; Lee and Baron, 2011).

Photosensitizers like aluminum phthalocyanine chloride provide photodynamic therapy (PDT) more effective (Dutta et al., 2005). It seems that strong attraction to the negatively charged parasitic membrane and high singlet oxygen with immunomodulating effect are the major factors in increasing the effect of PDT in the presence of photosensitizers (Akilov et al., 2006, 2007).

\section{$\mathrm{CO}_{2}$ laser}

$\mathrm{CO}_{2}$ laser has been used for topical treatment of CL. Results of different studies showed that $\mathrm{CO}_{2}$ laser is a good and effective treatment modality with rare and infrequent sequels (Asilian et al., 2004b, 2006).

The $\mathrm{CO}_{2}$ laser was more effective in treating dry-type cutaneous leishmaniasis than combined cryotherapy and intralesional glucantime and resulted in a shorter healing time with a single treatment session (Shamsi Meymandi et al., 2011).

\section{Other suggested topical treatment}

Nitric oxide

Nitric oxide (NO) synthesized by macrophages, a key molecule in defence mechanism, has also a microbicidal activity. It was generated non-enzymatically from nitrite and in high doses it may produce toxic effect to macrophages (Davidson et al., 2000). Topical application revealed good results for the treatment of CL using glyceryl trinitrate as an exogenous donor (Zeina et al., 1997a). Other exogenous donors with leishmanicidal activity were reported (de Souza et al., 2006). Topical nitric oxide associated with cryotherapy did not provide a better healing compared to cryotherapy alone (Jowkar et al., 2012).

\section{Honey}

Topical honey for treatment of cutaneous leishmaniasis was introduced to the literature in 1997, although it was used as an alternative therapy by lay people around the world (Zeina et al., 1997b). Its precise mechanism of action is not known but it seems to be effective on collagen formation, prevention of wound 
dehiscence, production of granulation tissue, epithelialization and minimal scar formation of the wounds (Nilforoushzadeh et al., 2007). Honey was found to have an antimicrobial effect and that it can increase the speed of wound healing. The physicochemical characteristics like osmotic effect or $\mathrm{pH}$ may aid to its antibacterial activity (Lusby et al., 2002). Locally and commercially produced honey is not able to inhibit bacterial growth completely (Lusby et al., 2005). A recently published clinical trial showed no additive effect of combination therapy of honey and glucantime in 45 patients (Nilforoushzadeh et al., 2007). Topical hot or boiled honey was found to be probably more effective in some parts of the world (Beyrer et al., 2007; Nilforoushzadeh et al., 2007).

\section{Herbal extracts}

Herbal extracts from several plants have been examined against the promastigote and/or amastigote forms of the parasite in culture media and animal models, respectively; but most of them have not been clinically trialled. An example of those is a topical herbal extract called Z-HE, used in Iran (Zerehsaz et al., 1999) without any confirmatory reports from other centres worldwide (Momeni and Aminjavaheri, 2000). Studies on herbal extracts being currently performed can be expected to present further and new data possibly valuable for the treatment of leishmaniasis.

Morphine

Topical inoculation of morphine was supposed to be effective in the treatment of CL (Alavi-Naini, 2008). The in vitro survey revealed that morphine in some concentrations is effective on promastigote forms of $L$. major; however, in the in vivo evaluation, no effectiveness was observed on experimental $C L$ in $B A L B / c$ mice (Alavi-Naini et al., 2010). Considering the in vitro results, effects of morphine in various concentrations is worth evaluation in animal models.

\section{Conclusion}

Cutaneous leishmaniasis is still a major health problem especially in countries with low socioeconomic development. Although pentavalent antimony compounds are still the standard, basic and first line of treatment, incomplete response to treatment and appearance of drug resistance of the causative parasite are major concerns. Sometimes physicians become confused for selecting the most appropriate therapeutic option. Easy drug availability, duration of treatment, cost and medical care staffs experienced in using new treatment modalities are the major important factors in endemic regions. It should be reminded that the assessment of the efficacy of any therapeutic agent in a self-healing disease such as $C L$ is very difficult. Welldesigned, double-blind, randomized placebo controlled trials should be designed and conducted to find new effective treatments. 


\section{References}

Aguiar, M. G., Silva, D. L., Nunan, F. A., Nunan, E. A., Fernandes, A. P., Ferreira, L. A. (2009) Combined topical paromomycin and oral miltefosine treatment of mice experimentally infected with Leishmania (Leishmania) major leads to reduction in both lesion size and systemic parasite burdens. J. Antimicrob. Chemother. 64(6), 1234-1240.

Akilov, O. E., Kosaka, S., O’Riordan, K., Song, X., Sherwood, M., Flotte, T. J., Foley, J. W., Hasan, T. (2006) The role of photosensitizer molecular charge and structure on the efficacy of photodynamic therapy against Leishmania parasites. Chem. Biol. 13(8), 839-847.

Akilov, O. E., Kosaka, S., O'Riordan, K., Hasan, T. (2007) Photodynamic therapy for cutaneous leishmaniasis: The effectiveness of topical phenothiaziniums in parasite eradication and Th1 immune response stimulation. Photochem. Photobiol. Sci. 6(10), 1067-1075.

Alavi-Naini, R. (2008) Topical morphine for the treatment of cutaneous leishmaniasis. Med. Hypotheses 70(1), 81-84.

Alavi-Naini, R., Fazaeli, A., Pejman, B. M., Ansari, A., Fouladi, B., Khamesipour, A. (2010) The efficacy of morphine on murine (BALB/C) cutaneous leishmaniasis. Iran. J. Infect. Dis. Trop. Med. 14(46), 15-21.

al-Majali, O., Routh, H. B., Abuloham, O., Bhowmik, K. R., Muhsen, M., Hebeheba, H. (1997) A 2-year study of liquid nitrogen therapy in cutaneous leishmaniasis. Int. J. Dermatol. 36(6), 460-462.

Al-Mutairi, N., Alshiltawy, M., El Khalawany, M., Joshi, A., Eassa, B. I., Manchanda, Y., Gomaa, S., Darwish, I., Rijhwani, M. (2009) Tropical medicine rounds: Treatment of Old World cutaneous leishmaniasis with dapsone, itraconazole, cryotherapy, and imiquimod, alone and in combination. Int. J. Dermatol. 48(8), 862-869.

Amato, V. S., Rabello, A., Rotondo-Silva, A., Kono, A., Maldonado, T. P. H., Alves, I. C., Floeter-Winter, L. M., Neto, V. A., Shikanai-Yasuda, M. A. (2004) Successful treatment of cutaneous leishmaniasis with lipid formulations of amphotericin B in two immunocompromised patients. Acta Trop. 92(2), 127-132.

Arana, B., Rizzo, N., Diaz, A. (2001a) Chemotherapy of cutaneous leishmaniasis: a review. Med. Microbiol. Immunol. 190(1-2), 93-95.

Arana, B. A., Mendoza, C. E., Rizzo, N. R., Kroeger, A. (2001b) Randomized, controlled, double-blind trial of topical treatment of cutaneous leishmaniasis with paromomycin plus methylbenzethonium chloride ointment in Guatemala. Am. J. Trop. Med. Hyg. 65(5), 466-470.

Arevalo, I., Ward, B., Miller, R., Tze-Chiang, M., Najar, E., Alvarez, E., Matlashewski, G., Llanos-Cuentas, A. (2001) Successful treatment of drug-resistant cutaneous leishmaniasis in humans by use of imiquimod, an immunomodulator. Clin. Infect. Dis. 33(11), 1847-1851.

Arevalo, I., Tulliano, G., Quispe, A., Spaeth, G., Matlashewski, G., Llanos-Cuentas, A., Pollack, H. (2007) Role of imiquimod and parenteral meglumine antimoniate in the initial treatment of cutaneous leishmaniasis. Clin. Infect. Dis. 44(12), 1549-1554.

Armijos, R. X., Weigel, M. M., Calvopina, M., Mancheno, M., Rodriguez, R. (2004) Comparison of the effectiveness of two topical paromomycin treatments versus meglumine antimoniate for New World cutaneous leishmaniasis. Acta Trop. 91(2), 153-160.

Aronson, N. E., Wortmann, G. W., Byrne, W. R., Howard, R. S., Bernstein, W. B., Marovich, M. A., Polhemus, M. E., Yoon, I. K., Hummer, K. A., Gasser, R. A. Jr., Oster, C. N., Benson, P. M. (2010) A randomized controlled trial of local heat therapy versus intravenous sodium stibogluconate for the treatment of cutaneous Leishmania major infection. PLoS Negl. Trop. Dis. 4(3), e628.

Asilian, A., Davami, M. (2006) Comparison between the efficacy of photodynamic therapy and topical paromomycin in the treatment of Old World cutaneous leishmaniasis: a placebo-controlled, randomized clinical trial. Clin. Exp. Dermatol. 31(5), 634-637.

Asilian, A., Jalayer, T., Nilforooshzadeh, M., Ghassemi, R. L., Peto, R., Wayling, S., Olliaro, P., Modabber, F. 
(2003) Treatment of cutaneous leishmaniasis with aminosidine (paromomycin) ointment: double-blind, randomized trial in the Islamic Republic of Iran. Bull. World Health Organ. 81(5), 353-359.

Asilian, A., Sadeghinia, A., Faghihi, G., Momeni, A. (2004a) Comparative study of the efficacy of combined cryotherapy and intralesional meglumine antimoniate (Glucantime) vs. cryotherapy and intralesional meglumine antimoniate (Glucantime) alone for the treatment of cutaneous leishmaniasis. Int. J. Dermatol. 43(4), 281-283.

Asilian, A., Sharif, A., Faghihi, G., Enshaeieh, S., Shariati, F., Siadat, A. H. (2004b) Evaluation of $\mathrm{CO}_{2}$ laser efficacy in the treatment of cutaneous leishmaniasis. Int. J. Dermatol. 43(10), 736-738.

Asilian, A., Iraji, F., Hedaiti, H. R., Siadat, A. H., Enshaieh, S. (2006) Carbon dioxide laser for the treatment of lupoid cutaneous leishmaniasis (LCL): a case series of 24 patients. Dermatol. Online J. 12(2), 3.

Bassiouny, A., El Meshad, M., Talaat, M., Kutty, K., Metawaa, B. (1982) Cryosurgery in cutaneous leishmaniasis. Br. J. Dermatol. 107(4), 467-474.

Beyrer, C., Villar, J. C., Suwanvanichkij, V., Singh, S., Baral, S. D., Mills, E. J. (2007). Neglected diseases, civil conflicts, and the right to health. Lancet 370(9587), 619-627.

Bumb, R. A., Satoskar, A. R. (2011) Radiofrequency-induced heat therapy as first-line treatment for cutaneous leishmaniasis. Expert Rev. Anti Infect. Ther. 9(6), 623-625.

Carneiro, G., Santos, D. C., Oliveira, M. C., Fernandes, A. P., Ferreira, L. S., Ramaldes, G. A., Nunan, E. A., Ferreira, L. A. (2010) Topical delivery and in vivo antileishmanial activity of paromomycin-loaded liposomes for treatment of cutaneous leishmaniasis. J. Liposome Res. 20(1), 16-23.

Croft, S. L., Yardley, V. (2002) Chemotherapy of leishmaniasis. Curr. Pharm. Des. 8(4), 319-342.

Croft, S. L., Sundar, S., Fairlamb, A. H. (2006) Drug resistance in leishmaniasis. Clin. Microbiol. Rev. 19(1), 111-126.

Davidson, R. N., Russo, R. (1994) Relapse of visceral leishmaniasis in patients who were coinfected with human immunodeficiency virus and who received treatment with liposomal amphotericin B. Clin. Infect. Dis. 19(3), 560.

Davidson, R. N., Yardley, V., Croft, S. L., Konecny, P., Benjamin, N. (2000) A topical nitric oxide-generating therapy for cutaneous leishmaniasis. Trans. R. Soc. Trop. Med. Hyg. 94(3), 319-322.

de Souza, G. F., Yokoyama-Yasunaka, J. K., Seabra, A. B., Miguel, D. C., de Oliveira, M. G., Uliana, S. R. (2006) Leishmanicidal activity of primary S-nitrosothiols against Leishmania major and Leishmania amazonensis: implications for the treatment of cutaneous leishmaniasis. Nitric Oxide 15(3), 209-216.

Dutta, S., Ray, D., Kolli, B. K., Chang, K. P. (2005) Photodynamic sensitization of Leishmania amazonensis in both extracellular and intracellular stages with aluminum phthalocyanine chloride for photolysis in vitro. Antimicrob. Agents Chemother. 49(11), 4474-4484.

el Darouti, M. A., al Rubaie, S. M. (1990) Cutaneous leishmaniasis. Treatment with combined cryotherapy and intralesional stibogluconate injection. Int. J. Dermatol. 29(1), 56-59.

El-On, J., Jacobs, G. P., Witztum, E., Greenblatt, C. L. (1984) Development of topical treatment for cutaneous leishmaniasis caused by Leishmania major in experimental animals. Antimicrob. Agents Chemother. 26(5), $745-751$.

El-On, J., Halevy, S., Grunwald, M. H., Weinrauch, L. (1992) Topical treatment of Old World cutaneous leishmaniasis caused by Leishmania major: a double-blind control study. J. Am. Acad. Dermatol. 27(2 Pt 1), 227-231.

Faghihi, G., Tavakoli-kia, R. (2003) Treatment of cutaneous leishmaniasis with either topical paromomycin or intralesional meglumine antimoniate. Clin. Exp. Dermatol. 28(1), 13-16.

Fazaeli, A., Fouladi, B., Hashemi-Shahri, S. M., Sharifi, I. (2008) Clinical features of cutaneous leishmaniasis and direct PCR based identification of parasite species in a new focus in south-east of Iran. Iranian J. Publ. Health 37, 44-51. 
Fazaeli, A., Fouladi, B., Sharifi, I. (2009) Emergence of cutaneous leishmaniasis in a border area at south-east of Iran: an epidemiological survey. J. Vector Borne Dis. 46(1), 36-42.

Fernández, M. M., Malchiodi, E. L., Algranati, I. D. (2011) Differential effects of paromomycin on ribosomes of Leishmania mexicana and mammalian cells. Antimicrob. Agents Chemother. 55(1), 86-93.

Firooz, A., Khamesipour, A., Ghoorchi, M. H., Nassiri-Kashani, M., Eskandari, S. E., Khatami, A., Hooshmand, B., Gorouhi, F., Rashighi-Firoozabadi, M., Dowlati, Y. (2006) Imiquimod in combination with meglumine antimoniate for cutaneous leishmaniasis: a randomized assessor-blind controlled trial. Arch. Dermatol. 142(12), 1575-1579.

Fouladi, B., Sharifi, I., Hashemi Shahri, M., Moradgholi, H. R., Sarabandi-No, A., Ebrahimzadeh, A., Fazaeli, A. (2007) Evaluation of a direct PCR in comparison with routine microscopy and in vitro culture for diagnosis of cutaneous leishmaniasis. J. Zahedan Univ. Med. Sci. Health Serv. 9(3), 181-189.

Frankenburg, S., Glick, D., Klaus, S., Barenholz, Y. (1998) Efficacious topical treatment for murine cutaneous leishmaniasis with ethanolic formulations of amphotericin B. Antimicrob. Agents Chemother. 42(12), 3092-3096.

Garnier, T., Brown, M. B., Lawrence, M. J., Croft, S. L. (2006) In-vitro and in-vivo studies on a topical formulation of sitamaquine dihydrochloride for cutaneous leishmaniasis. J. Pharm. Pharmacol. 58(8), 1043-1054.

Garnier, T., Mantyla, A., Jarvinen, T., Lawrence, J., Brown, M., Croft, S. (2007) In vivo studies on the antileishmanial activity of buparvaquone and its prodrugs. J. Antimicrob. Chemother. 60(4), 802-810.

Glasser, J. S., Murray, C. K. (2011) Central nervous system toxicity associated with liposomal amphotericin B therapy for cutaneous leishmaniasis. Am. J. Trop. Med. Hyg. 84(4), 566-568.

González, U., Pinart, M., Reveiz, L., Alvar, J. (2008) Interventions for Old World cutaneous leishmaniasis. Cochrane Database Syst. Rev. (4), CD005067.

Grogl, M., Schuster, B. G., Ellis, W. Y., Berman, J. D. (1999) Successful topical treatment of murine cutaneous leishmaniasis with a combination of paromomycin (Aminosidine) and gentamicin. J. Parasitol. 85(2), 354-359.

Iraji, F., Sadeghinia, A. (2005) Efficacy of paromomycin ointment in the treatment of cutaneous leishmaniasis: results of a double-blind, randomized trial in Isfahan, Iran. Ann. Trop. Med. Parasitol. 99(1), 3-9.

Jha, T. K., Sundar, S., Thakur, C. P., Felton, J. M., Sabin, A. J., Horton, J. (2005) A phase II dose-ranging study of sitamaquine for the treatment of visceral leishmaniasis in India. Am. J. Trop. Med. Hyg. 73(6), 1005-1011.

Jowkar, F., Dehghani, F., Jamshidzadeh, A. (2012) Is topical nitric oxide and cryotherapy more effective than cryotherapy in the treatment of old world cutaneous leishmaniasis? J. Dermatolog. Treat. 23(2), 131-135.

Khalili, G., Dobakhti, F., Mahmoudzadeh-Niknam, H., Khaze, V., Partovi, F. (2011) Immunotherapy with Imiquimod increases the efficacy of Glucantime therapy of Leishmania major infection. Iran. J. Immunol. 8(1), 45-51.

Larbi, E. B., al-Khawajah, A., al-Gindan, Y., Jain, S., Abahusain, A., al-Zayer, A. (1995) A randomized, doubleblind, clinical trial of topical clotrimazole versus miconazole for treatment of cutaneous leishmaniasis in the eastern province of Saudi Arabia. Am. J. Trop. Med. Hyg. 52(2), 166-168.

Layegh, P., Pezeshkpoor, F., Soruri, A. H., Naviafar, P., Moghiman, T. (2009) Efficacy of cryotherapy versus intralesional meglumine antimoniate (glucantime) for treatment of cutaneous leishmaniasis in children. Am. J. Trop. Med. Hyg. 80(2), 172-175.

Layegh, P., Rajabi, O., Jafari, M. R., Emamgholi Tabar Malekshah, P., Moghiman, T., Ashraf, H., Salari, R. (2011) Efficacy of topical liposomal amphotericin B versus intralesional meglumine antimoniate (Glucantime) in the treatment of cutaneous leishmaniasis. J. Parasitol. Res. 2011, 656523. (Epub)

Lee, Y., Baron, E. D. (2011) Photodynamic therapy: current evidence and applications in dermatology. Semin. Cutan. Med. Surg. 30(4), 199-209. 
Leibovici, V., Aram, H. (1986) Cryotherapy in acute cutaneous leishmaniasis. Int. J. Dermatol. 25(7), 473-475. Loiseau, P. M., Cojean, S., Schrével, J. J. (2011) Sitamaquine as a putative antileishmanial drug candidate: from the mechanism of action to the risk of drug resistance. Parasite 18(2), 115-119.

Lusby, P. E., Coombes, A., Wilkinson, J. M. (2002) Honey: a potent agent for wound healing? J. Wound Ostomy Continence Nurs. 29(6), 295-300.

Lusby, P. E., Coombes, A. L., Wilkinson, J. M. (2005) Bactericidal activity of different honeys against pathogenic bacteria. Arch. Med. Res. 36(5), 464-467.

Mantyla, A., Garnier, T., Rautio, J., Nevalainen, T., Vepsälainen, J., Koskinen, A., Croft, S. L., Järvinen, T. (2004) Synthesis, in vitro evaluation, and antileishmanial activity of water-soluble prodrugs of buparvaquone. J. Med. Chem. 47(1), 188-195.

Miranda-Verastegui, C., Llanos-Cuentas, A., Arevalo, I., Ward, B. J., Matlashewski, G. (2005) Randomized, double-blind clinical trial of topical imiquimod $5 \%$ with parenteral meglumine antimoniate in the treatment of cutaneous leishmaniasis in Peru. Clin. Infect. Dis. 40(10), 1395-1403.

Momeni, A. Z., Aminjavaheri, M. (2000) A double-blind randomized clinical trial of a topical herbal extract (Z-he) vs. systemic meglumine antimonate. Int. J. Dermatol. 39(11), 880.

Munir, A., Janjua, S. A., Hussain, I. (2008) Clinical efficacy of intramuscular meglumine antimoniate alone and in combination with intralesional meglumine antimoniate in the treatment of old world cutaneous leishmaniasis. Acta Dermatovenerol. Croat. 16(2), 60-64.

Mussi, S. V., Fernandes, A. P., Ferreira, L. A. (2007) Comparative study of the efficacy of formulations containing fluconazole or paromomycin for topical treatment of infections by Leishmania (Leishmania) major and Leishmania (Leishmania) amazonensis. Parasitol. Res. 100(6), 1221-1226.

Neva, F. A., Ponce, C., Ponce, E., Kreutzer, R., Modabber, F., Olliaro, P. (1997) Non-ulcerative cutaneous leishmaniasis in Honduras fails to respond to topical paromomycin. Trans. R. Soc. Trop. Med. Hyg. 91(4), 473-475.

Nilforoushzadeh, M. A., Jaffary, F., Moradi, S., Derakhshan, R., Haftbaradaran, E. (2007) Effect of topical honey application along with intralesional injection of glucantime in the treatment of cutaneous leishmaniasis. BMC Complement. Altern. Med. 7, 13.

Ouellette, M., Drummelsmith, J., Papadopoulou, B. (2004) Leishmaniasis: drugs in the clinic, resistance and new developments. Drug Resist. Update. 7, 257-266.

Panagiotopoulos, A., Stavropoulos, P. G., Hasapi, V., Papakonstantinou, A. M., Petridis, A., Katsambas, A. (2005) Treatment of cutaneous leishmaniasis with cryosurgery. Int. J. Dermatol. 44(9), 749-752.

Proffitt, R. T., Satorius, A., Chiang, S. M., Sullivan, L., Adler-Moore, J. P. (1991) Pharmacology and toxicology of a liposomal formulation of amphotericin B (AmBisome) in rodents. J. Antimicrob. Chemother. 28, 49-61 (Suppl. B).

Reithinger, R., Mohsen, M., Aadil, K., Sidiqi, M., Erasmus, P., Coleman, P. G. (2003) Anthroponotic cutaneous leishmaniasis, Kabul, Afghanistan. Emerg. Infect. Dis. 9(6), 727-729.

Reithinger, R., Mohsen, M., Wahid, M., Bismullah, M., Quinnell, R. J., Davies, C. R., Kolaczinski, J., David, J. R. (2005) Efficacy of thermotherapy to treat cutaneous leishmaniasis caused by Leishmania tropica in Kabul, Afghanistan: a randomized, controlled trial. Clin. Infect. Dis. 40(8), 1148-1155.

Reithinger, R., Dujardin, J. C., Louzir, H., Pirmez, C., Alexander, B., Brooker, S. (2007) Cutaneous leishmaniasis. Lancet Infect. Dis. 7(9), 581-596.

Rodrigues, A. M., Hueb, M., Santos, T. A., Fontes, C. J. (2006) Factors associated with treatment failure of cutaneous leishmaniasis with meglumine antimoniate. Rev. Soc. Bras. Med. Trop. 39(2), 139-145.

Seeberger, J., Daoud, S., Pammer, J. (2003) Transient effect of topical treatment of cutaneous leishmaniasis with imiquimod. Int. J. Dermatol. 42(7), 576-579.

Shamsi Meymandi, S., Zandi, S., Aghaie, H., Heshmatkhah, A. (2011) Efficacy of CO(2) laser for treatment 
of anthroponotic cutaneous leishmaniasis, compared with combination of cryotherapy and intralesional meglumine antimoniate. J. Eur. Acad. Dermatol. Venereol. 25(5), 587-591.

Shazad, B., Abbaszadeh, B., Khamesipour, A. (2005) Comparison of topical paromomycin sulfate (twice/day) with intralesional meglumine antimoniate for the treatment of cutaneous leishmaniasis caused by $L$. major. Eur. J. Dermatol. 15(2), 85-87.

Singh, S.,Sivakumar, R. (2004) Challenges and new discoveries in the treatment of leishmaniasis. J. Infect. Chemother. 10(6), 307-315.

Stanimirovic, A., Stipic, T., Skerlev, M., Basta-Juzbasic, A. (1999) Treatment of cutaneous leishmaniasis with 20\% paromomycin ointment. J. Eur. Acad. Dermatol. Venereol. 13(3), 214-217.

Stevens, D. A. (1994) Overview of amphotericin B colloidal dispersion (amphocil). J. Infect. 28, 45-49 (Suppl. 1). Storer, E., Wayte, J. (2005) Cutaneous leishmaniasis in Afghani refugees. Australas. J. Dermatol. 46(2), 80-83.

Sundar, S., Rai, M. (2002) Advances in the treatment of leishmaniasis. Curr. Opin. Infect. Dis. 15(6), 593-598.

Sundar, S., Jha, T. K., Thakur, C. P., Mishra, M., Singh, V. P., Buffels, R. (2003) Single-dose liposomal amphotericin B in the treatment of visceral leishmaniasis in India: a multicenter study. Clin. Infect. Dis. 37(6), 800-804.

Sundar, S., Chakravarty, J., Rai, V. K., Agrawal, N., Singh, S. P., Chauhan, V., Murray, H. W. (2007) Amphotericin B treatment for Indian visceral leishmaniasis: response to 15 daily versus alternate-day infusions. Clin. Infect. Dis. 45(5), 556-561.

Uzun, S., Durdu, M., Culha, G., Allahverdiyev, A. M., Memisoglu, H. R. (2004) Clinical features, epidemiology, and efficacy and safety of intralesional antimony treatment of cutaneous leishmaniasis: recent experience in Turkey. J. Parasitol. 90(4), 853-859.

van Thiel, P. P., Leenstra, T., de Vries, H. J., van der Sluis, A., van Gool, T., Krull, A. C., van Vugt, M., de Vries, P. J., Zeegelaar, J. E., Bart, A., van der Meide, W. F., Schallig, H. D., Faber, W. R., Kager, P. A. (2010) Cutaneous leishmaniasis (Leishmania major infection) in Dutch troops deployed in northern Afghanistan: epidemiology, clinical aspects, and treatment. Am. J. Trop. Med. Hyg. 83(6), 1295-1300.

Vega, J. C., Sanchez, B. F., Montero, L. M., Montaña, R., del Pilar Mahecha, M., Dueñes, B., Baron, A. R., Reithinger, R. (2009) The efficacy of thermotherapy to treat cutaneous leishmaniasis in Colombia: a comparative observational study in an operational setting. Trans. R. Soc. Trop. Med. Hyg. 103(7), 703-706.

Wasan, K. M., Sivak, O., Rosland, M., Risovic, V., Bartlett, K. (2007) Assessing the antifungal activity, pharmacokinetics, and tissue distribution of amphotericin B following the administration of Abelcet and AmBisome in combination with caspofungin to rats infected with Aspergillus fumigatus. J. Pharm. Sci. 96(7), 1737-1747.

Yaghoobi-Ershadi, M. R., Jafari, R., Hanafi-Bojd, A. A. (2004) A new epidemic focus of zoonotic cutaneous leishmaniasis in central Iran. Ann. Saudi Med. 24(2), 98-101.

Zeina, B., Zohra, B. I., al-Assad, S. (1997a) Topical glyceryl trinitrate: a possible treatment for cutaneous leishmaniasis. Clin. Exp. Dermatol. 22(5), 244-245.

Zeina, B., Banfield, C., al-Assad, S. (1997b) The effects of honey on Leishmania parasites: an in vitro study. Trop. Doct. 27, 36-38 (Suppl. 1).

Zerehsaz, F., Salmanpour, R., Hanjani, F., Ardehali, S., Panjehshahin, M. R., Tabei, S. Z., Tabatabaee, H. R. (1999) A double-blind randomized clinical trial of a topical herbal extract (Z-HE) vs. systemic meglumine antimoniate for the treatment of cutaneous leishmaniasis in Iran. Int. J. Dermatol. 38, 610-612.

Zvulunov, A., Cagnano, E., Frankenburg, S., Barenholz, Y., Vardy, D. (2003) Topical treatment of persistent cutaneous leishmaniasis with ethanolic lipid amphotericin B. Pediatr. Infect. Dis. J. 22(6), 567-569. 